Article

\title{
Comprehensive Security: The Opportunities and Challenges of Incorporating Environmental Threats in Security Policy
}

\author{
Helmi Räisänen ${ }^{1,2,3, *}$, Emma Hakala ${ }^{4,5,6}$, Jussi T. Eronen ${ }^{2,3,6}$, Janne I. Hukkinen ${ }^{1,2}$ and Mikko J. Virtanen ${ }^{7}$ \\ ${ }^{1}$ Environmental Policy Research Group (EPRG), Faculty of Social Sciences, University of Helsinki, Finland; \\ E-Mails: helmi.raisanen@helsinki.fi (H.R.), janne.i.hukkinen@helsinki.fi (J.I.H.) \\ ${ }^{2}$ Helsinki Institute of Sustainability Science (HELSUS), University of Helsinki, Finland; \\ E-Mail: jussi.t.eronen@helsinki.fi (J.T.E.) \\ ${ }^{3}$ Faculty of Biological and Environmental Sciences, University of Helsinki, Finland \\ ${ }^{4}$ Global Security Programme, Finnish Institute of International Affairs, Finland; E-Mail: emma.hakala@helsinki.fi \\ ${ }^{5}$ Erik Castrén Institute, Faculty of Law, University of Helsinki, Finland \\ ${ }^{6}$ BIOS Research Unit, Helsinki, Finland \\ ${ }^{7}$ Faculty of Social Sciences, University of Helsinki, Finland; E-mail: mikko.jz.virtanen@helsinki.fi \\ * Corresponding author
}

Submitted: 23 April 2021 | Accepted: 24 June 2021 | Published: 22 October 2021

\begin{abstract}
In security and foreign policy discourse, environmental issues have been discussed increasingly as security threats that require immediate action. Yet, as the traditional security sector does not provide straightforward means to deal with climate change and other environmental issues, this has prompted concerns over undue securitisation and ill-placed extreme measures. We argue that an effective policy to address foreseeable environmental security threats can only be developed and maintained by ensuring that it remains resolutely within the domain of civil society. In this article, we consider the case of Finland, where the policy concept of comprehensive security has been presented as the official guideline for security and preparedness activities in different sectors. Comprehensive security aims to safeguard the vital functions of society through cooperation between authorities, business operators, organisations, and citizens. We analyse the opportunities and challenges of Finland's comprehensive security policy in addressing environmental changes through a three-level framework of local, geopolitical and structural security impacts. Our empirical evidence is based on a set of expert interviews $(n=40)$ that represent a wide range of fields relevant to unconventional security issues. We find that the Finnish comprehensive security model provides an example of a wide and inclusive perspective to security which would allow for taking into account environmental security concerns. However, due to major challenges in the implementation of the model, it does not fully incorporate the long-term, cross-sectoral, and cascading aspects of environmental threats. This weakens Finland's preparedness against climate change which currently poses some of the most urgent environmental security problems.
\end{abstract}

\section{Keywords}

climate change; comprehensive security; environmental policy; environmental security; security policy

\section{Issue}

This article is part of the issue "Climate Change and Security" edited by Yasuko Kameyama (National Institute for Environmental Studies, Japan) and Yukari Takamura (University of Tokyo, Japan).

(C) 2021 by the authors; licensee Cogitatio (Lisbon, Portugal). This article is licensed under a Creative Commons Attribution 4.0 International License (CC BY).

\section{Introduction}

Global environmental deterioration and resource depletion have for decades been recognized as increasingly central considerations in security policy (e.g., U.S.
Council on Environmental Quality and Department of State, 1982), and the issue has gained international recognition, including several debates at the United Nations Security Council (Scott, 2015). Research suggests that environmental change affects security through 
its impacts on conflicts (Mach et al., 2019), livelihood and food security (Adger, 2000), health (Price-Smith, 2002), forced migration (Adger \& de Campos, 2020; Warner et al., 2010), or international power relations and geopolitics (Dalby, 2020; Selby \& Hoffmann, 2014), among others. Increasing evidence in recent years of climate-induced natural catastrophes indicates the Earth has entered an era of chronic environmental crises (e.g., Intergovernmental Panel on Climate Change, 2018). Yet concrete environmental security policies have not emerged in a systematic way (Hakala et al., 2019a). At the same time, concerns have been expressed about the securitisation of environmental policy as it may restrict democratic processes and lead to exceptional measures (Aradau, 2004; Buzan et al., 1998). We share these concerns but argue that for policy to be effective in addressing the foreseeable environmental security threats, it needs to remain resolutely within the domain of civil society.

In this article, we use Finland as a case study to show that the concept of comprehensive security, which currently guides the country's preparedness activities in different sectors of the civil society, offers a promising policy model for addressing environmental threats without hard securitisation. Most importantly, as it is based on the idea of wide cooperation among different sectors, comprehensive security takes a broad and inclusive perspective on security. The concept can be thought to represent an ongoing attempt to widen the range of security actors in Finland. Previous analyses have suggested that the field of security may need to open to new issues, actors, and practices in order to deal with environmental threats (e.g., Floyd, 2016; Oels, 2012; Trombetta, 2010). We therefore undertake a critical diagnosis of the Finnish comprehensive security model in light of earlier theorizations of widening security. While our analysis identifies several opportunities of the model, we also find challenges in its implementation. The lessons we draw from the Finnish case have wider interest as the concept of comprehensive security could be applied in other countries.

Comprehensive security is a policy concept that has become a key feature of Finnish security policy during the 2010s. It forms the basis for national preparedness efforts and for taking necessary actions in the event of disruptions. The comprehensive security model is detailed in the Security Strategy for Society (Prime Minister's Office, 2017), where it is defined as a cross-sectoral cooperation model which aims to ensure the vital functions of society, bringing the authorities, the business community, organisations, and citizens to work together. The vital functions are identified as follows: leadership; international and EU activities; defence capability; internal security; economy, infrastructure and security of supply; functional capacity of the population and services; and psychological resilience (Prime Minister's Office, 2017). Cooperation within the model ensures that "actors share and analyse security information, prepare joint plans, as well as train and work together" (Prime Minister's Office, 2017, p. 5). Each administrative branch is responsible for implementing the strategy within its competence (Prime Minister's Office, 2017, p. 1). In emergency situations, "only minimum changes" to the lines of authority, organisation, and the division of responsibilities can be made (Prime Minister's Office, 2017, p. 11).

The Security Strategy for Society emphasises that rapid change in Finland's security environment has brought about new dynamic, transboundary threats that need to be countered with "new operating approaches and broad-based cooperation" (Prime Minister's Office, 2017, p. 6). Therefore, we interpret that the starting point of the Strategy is to provide a model for identifying new kinds of security threats. For example, hybrid influencing, which refers to multiple complementary methods aimed at exploiting the weaknesses of a targeted community, has emerged as a topic of interest (see National Defence Courses, 2018). Regarding the environment, the Strategy explicitly considers environmental emergency response, detection of environmental changes, and flood risk management (Prime Minister's Office, 2017, pp. 50, 70, 75). Previous research has considered the Finnish comprehensive security model from the perspectives of cyber security (Griffith, 2018), multiactor implementation and co-creation (Keskinen et al., 2017), and, for example, political viability and administrative operability (Branders, 2016). Analysis of implementing environmental measures within the model remain sparse.

According to the Security Strategy for Society (Prime Minister's Office, 2017, p. 28), the principles of comprehensive security can be summarized as follows:

- Comprehensive security is based on the principles of representative democracy and the rule of law.

- Lines of authority are based on statutory tasks and the responsibilities of competent authorities.

- Vital functions are secured by efficient and comprehensive use of society's resources, which is based on wide cooperation between the authorities, business operators, organisations, and citizens.

- Competent authorities' contingency and preparedness planning is supported by broad-based cooperation forums at different administrative levels.

- Comprehensive preparedness arrangements allow risks to be more effectively anticipated and resources to be used in a flexible manner. Planning of the recovery process ensures better resilience and preparedness.

- Preparedness has a European and international dimension.

- Preparedness is monitored and developed systematically, with the support of research information.

- Security information is widely disseminated.

Environmental security research has typically concentrated on policy documents. Yet our aim here is to 
analyse how environmental policies are put in practice, how the comprehensive security model is implemented, and how environmental change is acknowledged in the everyday of experts working on unconventional security issues. The implementation of the model is not straightforward but potentially frictional and interspersed within multiple levels and sectors of society. Furthermore, in their everyday work the experts face challenges in embedding environmental change in the comprehensive security model, and vice versa. To grasp these issues in detail, we analyse a data corpus of expert interviews $(n=40)$ that represent a wide range of fields relevant to unconventional security issues vis-à-vis environmental change. To address the multifaceted character of environmental security, we utilize a three-level framework developed by Hakala et al. (2019b) as an analytical tool. The framework differentiates between local impacts that directly affect individuals and communities; geopolitical impacts that are combined with transboundary and political factors; and structural impacts of mitigating and adapting to environmental change.

In the following sections, we first present analytical approaches to environmental security and introduce the three-level framework of environmental security impacts. After that we describe our materials and methods, and then proceed to the analysis, which is divided into four sections. First, we analyse the Finnish model of comprehensive security, and then deal with local, geopolitical, and structural environmental security impacts. We end with a concluding discussion.

\section{Analytical Approaches to Environmental Security}

The concept of environmental security has come to incorporate various topics and perspectives, but its overarching focus is on the interaction of threats between environmental change and society (e.g., Dalby, 2002). A considerable strand of the literature has analysed the role of environmental issues like resource scarcity and drought in the onset of conflicts (e.g., Diehl \& Gleditsch, 2001; Homer-Dixon, 1994), but emphasis has also been given to linkages between environmental change and human security, such as health, welfare, livelihoods, and food (e.g., Adger, 2000; Matthew et al., 2010; Sygna et al., 2013). Many of these analyses stress the importance of the societal context in which environmental security impacts take place. For example, environmental change is rarely the sole cause of conflict, but may increase its risk in combination with other socio-economic factors (Mach et al., 2019). The importance of contextualisation has also highlighted the need for country-specific or regional case studies (Selby \& Hoffmann, 2014). So far, cases have tended to focus on large countries or particularly vulnerable regions, suggesting that wider geographic coverage is useful.

The security impacts of environmental change may take place at various levels from the local to the global, occur suddenly or gradually, and affect individ- uals or entire societies. Their comprehensive character makes them difficult to anticipate or prevent coherently. As noted by Buzan et al. (1998), the traditional security sector does not provide the means to deal with environmental threats. This has prompted concerns over harmful securitisation which may lead to ill-placed extreme measures and de-politicization without necessarily offering effective solutions to environmental problems (e.g., Bettini, 2013). Securitisation-the linkage of new issues to security-has often been considered harmful because it may restrict democratic process and lead to exceptional and exclusionary courses of action (e.g., Aradau, 2004; Buzan et al., 1998). Yet environmental change does appear to have security consequences that cannot simply be disregarded (e.g., Dalby, 2020). Scholars like Trombetta (2010) and Oels (2012) have suggested that environmental issues could oblige the security sector to adopt new practices and a more inclusive cooperation with a wider group of actors. From this perspective, the crucial question is not merely whether environment should be linked to security but whether the linkage generates worthwhile measures to anticipate and prepare for new risks.

However, any effort to constructively build preparedness requires an understanding of the varied and comprehensive character of environmental threats. To address this, Hakala et al. (2019a, 2019b) suggest a framework that categorises environmental security into three levels of impacts: local, geopolitical, and structural. Local impacts are caused by environmental factors, such as extreme weather. They may impact human wellbeing both directly and through critical functions of society. Geopolitical impacts occur when political and international factors are coupled with environmental changes. These are indirect impacts that result from chains of events or cascading effects. For example, local impacts in one place can have consequences elsewhere through geopolitical or economic linkages (e.g., Challinor et al., 2018; Lawrence et al., 2020). Lastly, structural impacts result from the measures that are taken to mitigate and adapt to environmental change itself. It is assumed that in order to achieve sustainable and secure societies, wide structural changes in the economic and political systems are needed. For example, the energy system needs to be restructured in a way that allows for a comprehensive utilization of sustainable sources (see Chapin et al., 2011; Steffen et al., 2018). Such societal transformations are likely to challenge, for example, democratic decisionmaking and bring forward questions of socially just transition. Although urgent decarbonisation is vitally necessary, it may also have security impacts either locally or through international relations (Mirumachi et al., 2020; Selby, 2014).

Hakala et al. have used the three-level framework to analyse central Finnish security policy documents and state-commissioned research papers to see how different environmental security impacts are covered. They found that some linkages have been recognised at 
strategic level, but mostly, these have not been implemented in policy. Especially the lack of policies for geopolitical and structural security impacts reflects a wider gap in international policymaking and research on this topic (Hakala et al., 2019a, 2019b). Here, we analyse whether the Finnish model of comprehensive security has the potential to address these gaps.

\section{Materials and Methods}

In this article, we broaden the perspective of previous analyses of policy documents (Hakala et al., 2019a, 2019b) with extensive interview material to identify how environmental security impacts are being acknowledged and integrated into the Finnish model of comprehensive security. Additionally, to examine the potential of the model, we analysed the central policy document, the Security Strategy for Society (Prime Minister's Office, 2017). We assume that whereas policy documents in general guide the work of practitioners, the implementation of policies is not straightforward but potentially frictional as local modes of knowledge and experts' hands-on skills and practices do not match seamlessly with the policies. Although previous research has analysed the corpus of central security policy documents (Hakala et al., 2019a, 2019b), their implementation, concerning especially the environment, has not been studied in depth. Therefore, we posit that the detailed interview material is essential for nuanced understanding of the challenges and opportunities of incorporating environmental issues in security policy.

Our study is based on a corpus of interview material which was collected during the years 2018-2019 for the purpose of a larger multi-disciplinary research consortium focusing on the governance of wicked socioenvironmental disruption). The semi-structured interviews $(n=40)$ were conducted by the consortium researchers and the interviewees $(n=44)$ were selected to represent the diversity of Finland's resilience and adaptation infrastructure against disruptions. Therefore, experts and officials from diverse sectors, such as public authorities from different administrative branches, researchers from different disciplines, and representatives of private companies, were recruited to the final interviews (see the Supplementary File). All interviews were recorded and transcribed verbatim. The rich interview material has been widely used by the consortium researchers, for instance to trace the movement of climate knowledge in municipal organisations (Virtanen et al., 2021) and to identify specific organizational rhythmic discordances as barriers to climate change actions (Reinekoski et al., 2021).

For the specific purposes of this study, the interview material allowed the analysis of a range of security concerns beyond the traditional security field. Our analysis focused on environmental threats and risks in the experts' own field and measures taken to counter them. Informants' responsibilities, knowledge, and cooperation with other sectors were also studied in order to better understand the possible widening of the security field.

As a research method we employed content analysis, structured around the three-level framework of environmental security impacts (Hakala et al., 2019b) to systematise our qualitative work. The analysis was conducted in four interconnected phases: We first developed a coding system of different environmental security impacts based on the three-level framework, and then coded the raw data by employing the classification of impacts. During the analysis, quotations pertaining to each impact were also compiled. To verify the coding process, two of the authors performed the analysis work together. This stage of analysis helped us to identify successes and gaps in threat recognition. In the third phase, aided by previous research (Hakala et al., 2019b), we analysed the central policy document on comprehensive security (Prime Minister's Office, 2017) to identify the opportunities for integrating environmental issues in security policy. In the fourth and more interpretive phase of the analysis, we thematised the interview material to find recurrent challenges in the implementation of the comprehensive security model.

\section{Analysis}

\subsection{The Finnish Model of Comprehensive Security}

Analysing the Security Strategy for Society (Prime Minister's Office, 2017), we find several opportunities supporting the integration of environmental issues into security policymaking. First, all actors "taking part in coordinated security work" (Prime Minister's Office, 2017, p. 7) or closely supporting it are considered security actors. This is a broad definition, as security work is understood as preparedness activities like contingency planning, continuity management, advance preparations, training, and preparedness exercises (Prime Minister's Office, 2017, pp. 7-9). Second, the strategy calls for proactive instead of reactive preparedness. This requires coordination between foresight methods, research findings, and monitoring of changes in the operating environment (Prime Minister's Office, 2017, p. 10). Third, the implementation of comprehensive security is expected to take place through cross-sectoral cooperation between different administrative branches, authorities, and the business community, monitored by the multi-sectoral Security Committee (Prime Minister's Office, 2017, p. 11). Fourth, the model is expected to support all actors in their practical security work, also at the regional and local level (Prime Minister's Office, 2017, p. 27). In other words, the opportunities of the comprehensive security model can be summarised as a wide understanding of security actors, proactive outlook, cross-sectoral approach, and applicability at multiple levels.

Based on the interview material, some aspects of these opportunities have been realized. The interviewees acknowledge that preparedness and security 
practices have changed during recent decades to better tackle more "complicated and complex problems" like hybrid and cyber threats and climate change. Some of the experts who explicitly discuss the comprehensive security model appreciate it for including a wide range of actors, such as citizens and non-governmental organizations. To some extent, the cross-sectoral aspect of the model has been implemented: Several interviewees state that security and preparedness cooperation between authorities has improved on different governmental levels.

However, the interviews indicate that many opportunities of the comprehensive security model remain unused. Several interviewees recognise that interagency cooperation should be more extensive; hard and soft security sectors in particular should collaborate more. For example, an expert mentions that there is a gap between the security community and other sectors. Another expert further describes the challenges in incorporating environmental issues into the model as follows:

It is not discussed where the emphasis should be within comprehensive security.....Cyber security and hybrid influencing have been perhaps given particular importance. I think the way climate change is considered now is that it may increase extreme weather events ... but it is a whole other scene where that issue is dealt with.

This suggests that even in the comprehensive security model, environmental threats are mainly considered from a narrow perspective on climate change induced extreme weather events. These are short-term disruptions with direct causes, while indirect or structural security impacts of environmental change appear to be harder to acknowledge. However, the comprehensive security model has been more successful in recognising some complex, indirect impacts like hybrid influencing. One explanation for this may lie in the gap between hard security and other sectors. This echoes previous research which points out that it is mainly the traditional security actors and security researchers who discuss comprehensive security as a concept and consider what it might entail (Keskinen et al., 2017). Even though the Security Committee includes representatives from different ministries, including the Ministry of the Environment, it still seems that harder security threats get more attention.

Furthermore, Keskinen et al. (2017) suggest that the narrow conceptual focus might hinder the integration of a wide field of actors into the model in practice or it might misdirect their actions. In our material, those interviewees who explicitly refer to the comprehensive security model are either from the national level of administration or from some of the core security- or preparednessrelated organizations, such as the Finnish Border Guard, the Rescue Services and the Finnish National Rescue Association. In contrast, many of the local level environmental actors see security as something separate from their work and related only to the functions of the police or rescue services. This indicates that the concept of comprehensive security has not been widely adopted. It appears mainly to be the central authorities or traditional security actors who have a sense of ownership of the comprehensive security model-not the wider range of actors whom it, by definition, aims to integrate. As one expert contemplates: "[Comprehensive security] is such a top-level activity that, to a large extent, the concreteness of it is left for the practitioners and their networks."

In sum, it appears that the comprehensive security model is still largely dominated by the principles and organizations of hard security. This ties the environmental aspects of comprehensive security in a paralyzing bind between principle and practice: On one hand, environmental issues are largely absent from the comprehensive security model because the hard security organizations fail to see the practical relevance of environmental issues to security; on the other hand, the very absence of environmental issues from the model makes it impractical and abstract for the soft security organizations. This bind challenges many aspects of the opportunities of broad participation, proactive preparedness, cross-sectoral cooperation, and multi-level governance in comprehensive security. At the same time, our analysis indicates that the bind does not fully preclude environmental security impacts. Therefore, using the three-level framework of environmental security, we analyse how the opportunities of the comprehensive security model have been realised.

\subsection{Local Impacts}

Local environmental security impacts, particularly extreme weather events, are widely recognised in the interviews, and many experts expect more of them in the near future. They discuss storms, forest fires, heat waves, extreme winters, and floods as events that can affect critical infrastructure. Furthermore, the interviewees expect climate change to bring new pests, invasive species, and diseases, and they explicate that these may harm forestry and agriculture and pose direct health threats to humans. When it comes to implementation, the interviewees describe an extensive set of climate change mitigation measures and some explicitly link them to threats.

We argue that it has been the wide understanding of security actors which has made the extensive recognition of local impacts possible. As all sectors are obliged to engage in preparedness, risks are identified also beyond hard security issues. Extreme weather events are matched with more frequent and extensive preparedness actions in the fields of urban planning and environmental protection, for example. In other words, here a widening of the field of security actors, as suggested for example by Trombetta (2010), appears to enable more effective security planning in practice. However, according to the interviews, the implementation of the 
comprehensive security model at multiple levels suffers from the varying availability of resources in different municipalities. Additionally, there is diversity in whether adaptation or mitigation gets more attention.

The proactive outlook is notable in the way some fields have adapted to the changing environment in the long term. For example, warmer and wetter climate is changing infrastructure maintenance practices. However, according to several interviewees, there are still trade-offs between short-term and long-term thinking, caused by the tendency to consider climate change mitigation and adaptation separately. Short-term goals are largely prioritised over a more long-term perspective, whereas effective mitigation action today could reduce the need for increasing adaptation in the future. In practice, it appears to be difficult to set sectoral practices to a more comprehensive temporal context and to devise measures that would be consistent with both the need to mitigate climate change and to adapt to its inevitable impacts.

To summarize, the comprehensive security model seems not to have supported cross-sectoral coordination or proactive outlook to the extent it has been envisioned to. Particularly, as several interviewees recognize the need for more extensive cooperation between the adaptation experts and the mitigation experts, the crosssectoral aspect appears to not have been fully realised. The interviews echo the findings of previous research (Prime Minister's Office, 2016) which suggests that climate risks are not always followed systematically, and that measures to prevent them often lack resources or coordination. In other words, while environmental issues appear to be introduced into the comprehensive security and preparedness model, they are not cross-sectorally and proactively integrated in a way that would allow for purposeful implementation.

\subsection{Geopolitical Impacts}

Geopolitical environmental impacts are considered in about half of the interviews. The proactive outlook appears to be visible in the way the interviewees consider the global risk potential of environmental change. National-level experts in particular raise issues related to deteriorating international relations. According to the ministry-level experts, climate change is acknowledged as a "risk multiplier," increasingly seen as "one of the underlying factors" in conflicts and global migration. This is a clear recognition of wider international discussion about climate change as a threat multiplier, prompted particularly by actors in the traditional security field in the United States (e.g., CNA, 2007). For example, climate change can further erode volatile economic, political, and environmental conditions in already fragile areas (CNA, 2007, p. 44). In addition, the interviewees emphasize the role of a rules-based international order and multilateralism in the fight against climate change, but also remark that "in the current geopolitical circumstances it cannot be taken for granted that everyone is committed to the same cause." For example, new international environmental projects involving Russia are not funded due to the sanctions imposed by the EU. Overall, there appears to be an understanding that climate change affects geopolitics and that geopolitics in turn have an impact on the way climate change can be mitigated. However, the proactive outlook alone does not lead to a highly detailed analysis of risks. For example, the Arctic area is not discussed extensively in the interviews, except for one expert who reflects how the relevance of the area "has increased tremendously." This contrasts with previous research suggesting that growing interest in the Arctic region can increase geopolitical risks for Finland (Käpylä \& Mikkola, 2016).

The cross-sectoral approach to geopolitical impacts is not that evident in the material, with some exceptions. For example, only the representatives of a shipping company consider how extreme winters-with demanding icebreaking conditions-might pose "a problem for the security of supply" of industries. Others do not consider security of supply even though it is an important topic in Finnish foreign and security policy which emphasises Finland's reliance on global resource flows and supply chains (see Hakala et al., 2019a).

The way some experts discuss energy security implies that there is some cross-sectoral recognition of how energy transition can contribute to geopolitical goals. One expert points out that Finland should not be "politically naïve" when it comes to ongoing international gas pipe projects: They should be seen not only as environmental but security issues as well. This view can be supported by research suggesting that gas pipelines can be used as an instrument of geostrategic influence (see Laine, 2018). However, elsewhere in the material, as in Finnish policy discourse more generally (Laine, 2018), the impact of gas pipelines is seen as strictly environmental and separate from security or geopolitics. This reflects the kind of narrow understanding of security associated with the paralyzing bind discussed earlier, suggesting that a wider view of security actors has not emerged.

Traces of cross-sectoral, proactive, and multi-level perspectives are noticeable in the recognition of some cascading effects regarding health threats and migration. For example, a regional environmental health officer says that long-term preparedness with a global perspective must consider climate change and health threats, as global food supply chains, migration, and the warming climate make new pathogens possible in Finland. Several interviewees, especially from the municipal and regional level, make a passing reference to the potential of climate change to increase global migration. The tendency of these experts to consider the impacts of health and migration can be seen as an example of multi-level perspective. However, some still express the need for further action: "It would be beneficial for the municipalities too to recognize the global dimension - that's where significant threats lie, after all." 
Yet despite some application of the opportunities of the comprehensive security model, there is a lack of long-term thinking and acknowledgement of cascading effects. Therefore, the geopolitical environmental impacts are mainly seen in a sector-specific way and chains of events are not widely discussed. Impacts originating outside Finnish borders are not broadly considered. This appears to be another occurrence of the aforementioned paralyzing bind, as the broader, geopolitical aspects of environmental change are not fully conveyed into the security field. Meanwhile, the lack of dialogue with security actors may also hinder the ability of experts from other fields to identify impacts and developments that would be relevant for building preparedness. This also suggests that the recognition of environmental issues within the comprehensive security model has not led to the integration of the issue into the practice of security. Therefore, the model appears to fall short of so-called "climatisation" of the security field, proposed by Oels (2012), where security practices would be applied to climate change and climate professionals would participate in their application.

\subsection{Structural Impacts}

About half of the interviewees discuss structural change in some way. However, the majority only considers some aspects of the challenges that hinder wide societal transformation without addressing the consequences of the changes. The short-sightedness of decision-making appears to be a prominent problem, showing that there are challenges with the proactive outlook. For example, one expert describes how, little by little, "the saving potential of reducing energy consumption" has been internalized in their municipality, but if the reduction "requires making an investment first, it's not yet very clearly considered to save in the long run." Some national-level experts suggest climate models should be better utilized in the economic sector to anticipate future trends-especially if Finland wishes to secure its competitive advantage. Overall, some experts do recognize the need to consider structural changes in the long-term, but the material implies that this perspective has not been incorporated strongly into policymaking. Short-term economic goals tend to be prioritized over long-term ecological sustainability. This is short-sighted in light of research showing that without strong mitigation measures environmental change will lead to severe impacts on the global and therefore also on the Finnish economy (see Hakala et al., 2019b).

Several experts point out challenges in proactive thinking regarding the cultural and behavioural changes that are still needed and note that necessary measures are often deemed unpleasant. For example, they describe that "it is a lot easier to get people involved" in protecting the biodiversity of a local forest area than in acting against the more abstract threat of climate change through behavioural changes. Many of the experts underline the role of politicians and identify problems related to governance. They emphasise the importance of democratic participation but also argue that the readiness of the society to structural change depends on "political courage." However, the way in which severe environmental changes might affect democracy is not discussed, even though it can be expected that the transition is going to test democratic decision-making (Hakala et al., 2019b).

Furthermore, the material shows that the opportunities of the comprehensive security model have not been utilized to integrate environmental expertise into decision-making and governance. Some interviewees note that the tendency to ignore environmental change in decision-making may lead to unwanted pathdependencies, which suggests a lack of proactive thinking. The cross-sectoral and multi-level perspective of the comprehensive security model seems to be missed at the local level as, in some municipalities, environmental experts struggle to "get into the right tables and discussions" despite their willingness (see also Virtanen et al., 2021).

The lack of proactive and cross-sectoral thinking hinders the ability to see how present choices may lead to new threats in the future. Although some experts identify long-term developments in their own sector, such views do not appear to be adequately considered in strategic planning overall. For example, in the energy sector, experts note that the higher demand for battery technology may take a heavier toll on nature and that extreme winters pose "the biggest challenge for increasing renewable energy sources." Some interviewees acknowledge that the lack of anticipation in the forest sector, for example concerning future climate mitigation policies, might make heavy investments in woodbased bioeconomy misguided. The experts also point out that the tendency to neglect biodiversity issues in forestry means that "some sort of catastrophe is way more likely to happen" in the long run. These statements are related to the heated debate over forest management in Finland: The country's bioeconomy strategies are based on increasing forest harvest size while reaching climate mitigation targets would require forests to function as carbon sinks (see Toivanen, 2021).

There seem to be clear difficulties in applying the opportunities of the comprehensive security model to tackle structural impacts. Particularly, there appears to be a lack of widely shared proactive thinking, recognizing how the mitigation of environmental change will affect preparedness and security. Environmental experts are not included in the wide understanding of security actors, which serves to maintain the paralyzing bind.

\section{Concluding Discussion}

According to the interview and the document material, the comprehensive security model provides opportunities for integrating environmental issues into security 
policymaking-namely, its cross-sectoral approach, the proactive outlook, the wide understanding of security actors, and the applicability at multiple levels. The model has helped to organize a wide set of actors to answer complex, indirect threats like hybrid influencing. However, according to our analysis, the model has not been fully realized in practice, which hinders the actual integration of environmental threats. In the interview material overall, security seems to be understood in a rather conventional way and related to hard security actors. As the model stems largely from within the security sector, environmental aspects end up in a paralyzing bind between principle and practice. In our view, an actual widening of the security discussion has not taken place in the sense that the security sector would have adopted perspectives from other fields, as suggested in previous research (e.g., Oels, 2012; Trombetta, 2010).

Apart from the narrow understanding of security, we find that the main challenges for incorporating environmental issues into security policy are related to their long-term, cross-sectoral, and cascading character. The interviewees seem to hold a relatively static view of economic and societal systems. This does not enable an understanding needed to effectively address the roots and impacts of environmental change. There is a tendency to focus on the present-day implications of policymaking while ignoring their long-term impacts and the ability to adapt to future change. Although some of the interviewees do themselves point out the need to take into account the long-term, it is not fully incorporated into policymaking. Yet previous research (e.g., Chapin et al., 2011) shows that the mitigation of and adaptation to environmental change require major structural changes which need to be considered already in presentday decision-making. However, it seems that there is no widespread discussion among the interviewees about changing the way they plan for or make decisions about the unknowable future. This suggests that, contrary to the principles professed in the Strategy outlining comprehensive security, the ability to take into account the long-term in a proactive way is limited.

The comprehensive security model seems not to have supported cross-sectoral coordination to the extent intended. In particular, the failure to integrate environmental expertise into decision-making and governance at the municipal level means that there are challenges in positioning sectoral practices in a more comprehensive context. Effective coordination would be needed to devise measures that are consistent with both the need to mitigate climate change and to adapt to its inevitable impacts. However, the level of coordination varies greatly across municipalities. This suggests that, despite the stated aim of comprehensive security to work at multiple levels, there is no shared model for implementing cross-sectoral collaboration at different levels of governance.

There is a tendency to see the impacts of environmental change as local, sector-specific, and resulting from direct causes, whereas it seems to be more difficult to acknowledge that threats outside Finland could have strong local effects through chains of events. These challenges reflect the fact that there is little research on specific chains of events and their impacts. Yet recent literature shows that such cascading effects are increasingly important to consider (Challinor et al., 2018). In the Finnish case, the various indirect impacts may be more significant compared to direct local impacts.

Comprehensive security as a policy model gives rise to questions related to security theory, particularly securitisation. Rather than imposing ill-placed and exclusionary measures (as in Aradau, 2004; Bettini, 2013; Buzan et al., 1998), the model specifically aims to promote preparedness in order to maintain the prerequisites of democracy and safeguard the rights of the individuals. Even in emergency situations, the measures should adhere to the principle of the rule of law (Prime Minister's Office, 2017). In this sense, the model seems to support the kind of widening of security that takes place within the sphere of democratic decision-making (see also Hakala, 2020). In particular, this seems to coincide with Floyd's (2016) view that securitisation does not only take place through undemocratic exceptional measures but may also occur, for example, through new legislation or when a state's existing security apparatus is employed to deal with new issues. In other words, as Trombetta (2010) suggests, politicisation and securitisation can be simultaneous, non-exclusionary processes.

Meanwhile, there is no indication that the security sector would have attempted to take over civil society functions, as the comprehensive security model has not fully integrated actors beyond the traditional security field. However, it has also not been open to interaction with outside perspectives and practices that would be crucial for dealing with new kinds of threats. Similar observations have been made regarding the Finnish response to the multi-sectoral Covid-19 crisis (Mörttinen, 2021). This distance between the security sector and civil society remains a major obstacle to creating an effective environmental security policy.

In their present form, the society and its institutions are inadequately equipped to deal with environmental change. As evidenced by the paralyzing bind, societal structures may rather hinder than support the prevention of environmental threats. The hard security organizations that have tended to take control of the comprehensive security model acknowledge the principle of environmental security but fail to see its practical relevance, which only serves to alienate the more peripheral soft security organizations from the model. Although our task here is not to delineate potential remedies, we do see a need for institutional empowerment in the distributed model of comprehensive security. Adaptation to complex operational environments demands a feedback between shared situational awareness and empowered execution among the participating organizations (McChrystal et al., 2015). Applying this principle to the 
comprehensive security model, the hard security organizations should make better use of the existing cooperation forums, as described in Section 1, to ensure that all participating organizations share the same situational awareness. At the same time, the hard security organizations should accept decentralized managerial authority over environmental security across the relevant actors of comprehensive security. As our interviews indicate, the soft security organizations are after all the experts of environmental security.

\section{Acknowledgments}

The authors would like to thank two anonymous reviewers for their valuable comments. Funding from Academy of Finland grant 338553, 338558 and Academy of Finland's Strategic Research Council grants 312623, 312624 and 336253, and from Kone Foundation is gratefully acknowledged.

\section{Conflict of Interests}

The authors declare no conflict of interests.

\section{Supplementary Material}

Supplementary material for this article is available online in the format provided by the author (unedited).

\section{References}

Adger, W. N. (2000). Social and ecological resilience: Are they related? Progress in Human Geography, 24(3), 347-364.

Adger, W. N., \& de Campos, R. S. (2020). Climate-change disruptions to migration systems. In T. Bastia \& R. Skeldon (Eds.), Routledge handbook of migration and development (pp. 382-395). Routledge.

Aradau, C. (2004). Security and the democratic scene. Journal of International Relations and Development, 7(4), 388-413.

Bettini, G. (2013). Climate barbarians at the gate? A critique of apocalyptic narratives on 'climate refugees'. Geoforum, 45, 63-72.

Branders, M. (2016). Kokonainen turvallisuus? Kokonaisturvallisuuden poliittinen kelpoisuus ja hallinnollinen toteutettavuus [Complete security? Political viability and administrative operability of comprehensive security] [Doctoral thesis, Tampere University]. Trepo. http://urn.fi/URN:ISBN:978-951-44-9996-8

Buzan, B., Waever, O., \& de Wilde, J. (1998). Security: A new framework for analysis. Lynne Rienner Publishers.

Challinor, A. J., Adger, W. N., Benton, T. G., Conway, D., Joshi, M., \& Frame, D. (2018). Transmission of climate risks across sectors and borders. Philosophical Transactions of the Royal Society A, 376(2121), Article 20170301.
Chapin, F. S., Pickett, S. T., Power, M. E., Jackson, R. B., Carter, D. M., \& Duke, C. (2011). Earth stewardship: A strategy for social-ecological transformation to reverse planetary degradation. Journal of Environmental Studies and Sciences, 1, 44-53.

CNA. (2007). National security and the threat of climate change. https://www.cna.org/CNA_files/pdf/ National\%20Security\%20and\%20the\%20Threat\% 20of\%20Climate\%20Change.pdf

Dalby, S. (2002). Environmental security. University of Minnesota Press.

Dalby, S. (2020). Anthropocene geopolitics: Globalization, security, sustainability. University of Ottawa Press.

Diehl, P., \& Gleditsch, N. P. (Eds.) (2001). Environmental conflict: An anthology. Routledge.

Floyd, R. (2016). Extraordinary or ordinary emergency measures: What, and who, defines the 'success' of securitization? Cambridge Review of International Affairs, 29(2), 677-694.

Griffith, M. K. (2018). A comprehensive security approach: Bolstering Finnish cybersecurity capacity. Journal of Cyber Policy, 3(3), 407-429.

Hakala, E. (2020). Turvallistamisen uudet tuulet: IImastonmuutos osana Suomen kokonaisturvallisuuden toimintamallia [Changing weather for securitization: Climate change as a part of the Finnish model of comprehensive security]. Kosmopolis, 50(3), 8-22.

Hakala, E., Lähde, V., Majava, A., Toivanen, T., Vadén, T., Järvensivu, P., \& Eronen, J. T. (2019a). A lot of talk, but little action-The blind spots of Nordic environmental security policy. Sustainability, 11(8), Article 2379.

Hakala, E., Lähde, V., Majava, A., Toivanen, T., Vadén, T., Järvensivu, P., \& Eronen, J. T. (2019b). Northern warning lights: Ambiguities of environmental security in Finland and Sweden. Sustainability, 11(8), Article 2228.

Homer-Dixon, T. F. (1994). Environmental scarcities and violent conflict: Evidence from cases. International Security, 19(1), 5-40.

Intergovernmental Panel on Climate Change. (2018). Summary for policymakers. In V. Masson-Delmotte, P. Zhai, H.-O. Pörtner, D. Roberts, J. Skea, P. R. Shukla, A. Pirani, W. Moufouma-Okia, C. Péan, R. Pidcock, S. Connors, J. B. R. Matthews, Y. Chen, X. Zhou, M. I. Gomis, E. Lonnoy, T. Maycock, M. Tignor, \& T. Waterfield (Eds.), Global warming of $1.5^{\circ} \mathrm{C}$ (pp. 1-24). World Meteorological Organization.

Käpylä, J., \& Mikkola, H. (2016). The promise of the geoeconomic Arctic: A critical analysis. Asia Europe Journal, 14, 203-220.

Keskinen, M., Kantola, A., Mäkinen, J., \& Salonen, A. O. (2017). Miten yhteiskehittää kokonaisturvallisuutta? Tieteidenvälisiä näkemyksiä Winlandhankkeesta [How to co-develop comprehensive security? Interdisciplinary perspectives from Winlandproject]. Tiede Ja Ase, 75, 124-154.

Laine, J. (2018). The Ukraine crisis and ontological 
(in)security: Implications from a Finnish perspective. In G. Soroka \& T. Stepniewski (Eds.), Ukraine after Maidan: Revisiting domestic and regional security (pp. 63-92). Ibidem Press.

Lawrence, J., Blackett, P., \& Cradock-Henry, N. A. (2020). Cascading climate change impacts and implications. Climate Risk Management, 29, Article 100234.

Mach, K. J., Kraan, C. M., Adger, W. N., Buhaug, H., Burke, M., Fearon, J. D., Field, C. B., Hendrix, C. S., Maystadt, J.-M., O'Loughlin, J., Roessler, P., Scheffran, J., Schultz, K. A., \& von Uexkull, N. (2019). Climate as a risk factor for armed conflict. Nature, 571(7764), 193-197.

Matthew, R. A., Barnett, J., McDonald, B., \& O'Brien, K. L. (Eds.). (2010). Global environmental change and human security. MIT Press.

McChrystal, S., Collins, T., Silverman, D., \& Fussell, C. (2015). Team of teams: New rules of engagement for a complex world. Penguin.

Mirumachi, N., Sawas, A., \& Workman, M. (2020). Unveiling the security concerns of low carbon development: Climate security analysis of the undesirable and unintended effects of mitigation and adaptation. Climate and Development, 12(2), 97-109.

Mörttinen, M. (2021). Valtioneuvoston ydin kriisitilanteessa [The centre of government in crisis situation]. Sitra. https://media.sitra.fi/2021/01/ 13105819/valtioneuvoston-ydin-kriisitilanteessa.pdf National Defence Courses. (2018). Turvallinen Suomi [Secure Finland]. The Security Committee. https:// turvallisuuskomitea.fi/wp-content/uploads/2018/ 01/Turvallinen_Suomi_2018.pdf

Oels, A. (2012). From 'securitization' of climate change to 'climatization' of the security field: Comparing three theoretical perspectives. In J. Scheffran, M. Brzoska, H. G. Brauch, P. M. Link, \& J. Schilling (Eds.), Climate change, human security and violent conflict. Challenges for societal stability (pp. 185-205). Springer.

Price-Smith, A. T. (2002). The health of nations: Infectious disease, environmental change, and their effects on national security and development. MIT Press.

Prime Minister's Office. (2016). Keinot edistää sää- ja ilmastoriskien hallintaa [Measures to promote the management of weather and climate related risks] (Publications of the Government's analysis, assessment and research activities 47/2016).

Prime Minister's Office. (2017). The security strategy for society (Government Resolution 2.11.2017). https://turvallisuuskomitea.fi/wp-content/uploads/
2018/04/YTS_2017_english.pdf

Reinekoski, T., Lahikainen, L., Virtanen, M. J., \& Lehtonen, T.-K. (2021). Rhythms as barriers for establishing climate change expertise in Finnish municipalities. Manuscript submitted for publication.

Scott, S. V. (2015). Implications of climate change for the UN Security Council: Mapping the range of potential policy responses. International Affairs, 91(6), 1317-1333.

Selby, J. (2014). Positivist climate conflict research: A critique. Geopolitics, 19(4), 829-856.

Selby, J., \& Hoffmann, C. (2014). Rethinking climate change, conflict and security. Geopolitics, 19(4), 747-756.

Steffen, W., Rockström, J., Richardson, K., Lenton, T. M., Folke, C., Liverman, D., Summerhayes, C. P., Barnosky, A. D., Cornell, S. E., Crucifix, M., Donges, J. F., Fetzer, I., Lade, S. J., Scheffer, M., Winkelmann, R., \& Schellnhuber, H. J. (2018). Trajectories of the Earth System in the Anthropocene. Proceedings of the National Academy of Sciences, 115(33), 8252-8259.

Sygna, L., O'Brien, K., \& Wolf, J. (Eds.). (2013). A changing environment for human security: Transformative approaches to research, policy and action. Routledge.

Toivanen, T. (2021). A player bigger than its size: Finnish bioeconomy and forest policy in the era of global climate politics. In M. Backhouse, R. Lehmann, K. Lorenzen, M. Lühmann, J. Puder, F. Rodríguez, \& A. Tittor (Eds.), Bioeconomy and global inequalities: Socioecological perspectives on biomass sourcing and production (pp. 131-149). Palgrave Macmillan.

Trombetta, J. (2010). Rethinking the securitization of the environment: Old beliefs, new insights. In T. Balzacq (Ed.), Securitization theory: How security problems emerge and dissolve (pp. 135-149). Routledge.

U.S. Council on Environmental Quality and Department of State. (1982). The global 2000 report to the President: Entering the twenty-first century. Penguin.

Virtanen, M. J., Reinekoski, T., Lahikainen, L., \& Lehtonen, T.-K. (2021). Travels and trials of climate knowledge in Finnish municipalities. Science \& Technology Studies. Advance online publication. https://doi.org/ 10.23987/sts.97519

Warner, K., Hamza, M., Oliver-Smith, A., Renaud, F., \& Julca, A. (2010). Climate change, environmental degradation and migration. Natural Hazards, 55, 689-715.

\section{About the Authors}

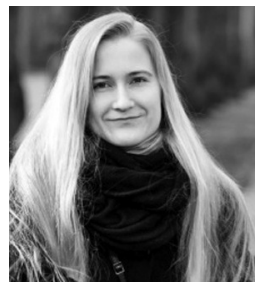

Helmi Räisänen is a doctoral candidate in environmental policy at the University of Helsinki. She holds a master's degree in social and cultural anthropology. Her research focuses on public authorities' preparedness practices and perceptions of uncertainty. Her interests also include simulation exercises and public health threats, such as pandemics. 

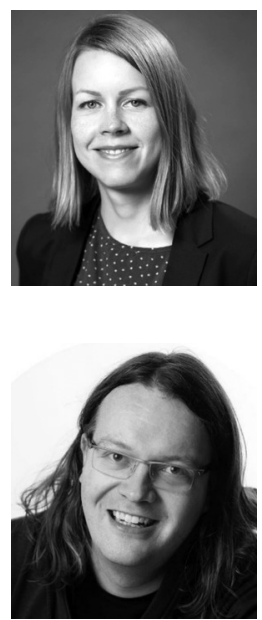

Jussi T. Eronen is an associate professor of long-term sustainability science at the Ecosystems and Environment research programme and Helsinki Institute of Sustainability Science at the University of Helsinki. He leads the Past Present Sustainability Research Unit (PAES), and he is a member of the BIOS Research Unit. His work focuses on long-term development of socio-ecological systems and natural resource use.

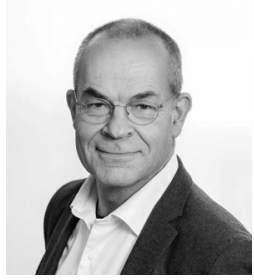

Janne I. Hukkinen is professor of environmental policy at the University of Helsinki. He studies the cognitive aspects of sustainability assessment and strategy, with empirical applications in participation, expertise and risk in environmental policy. Hukkinen is a member of The Finnish Society of Sciences and Letters, editorial board member of the journal Ecological Economics, and expert counsellor on the Environment for the Supreme Administrative Court of Finland. In addition to over 100 peer-reviewed scientific articles or book chapters, he is the author of Sustainability Networks (2008) and Institutions in Environmental Management (1999), both published by Routledge.

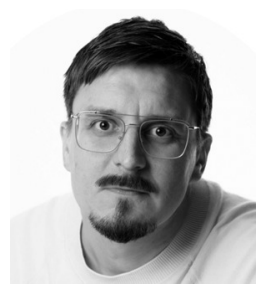

Mikko J. Virtanen with a PhD in social sciences, works as a university lecturer in sociology at the University of Helsinki, Finland, and holds a title of docent in sociology in the Faculty of Social Sciences at the University. His areas of expertise include social theory, social science methodology, sociology of health and illness, and science and technology studies. 